\title{
Vereinigung Medizinisch-Technischer Berufe in der DRG (VMTB)
}

- Donnerstag, 17. Mai 2012

17:00-18:00 Uhr Saal Bucky

Wir möchten Sie herzlich zu der jährlichen Mitgliederversammlung der Vereinigung der Medizinisch-Technischen Berufe in der DRG (VMTB) einladen.

\section{Tagesordnung}

- TOP 1 Begrüßung und Genehmigung der Tagesordnung

- TOP 2 Tätigkeitsbericht der Vorsitzenden

- TOP 3 Vorstellung neu geplanter Fortbildungsveranstaltungen und Aktivitäten
- TOP 4 Erhöhung des Mitgliedsbeitrags ab 2013

- TOP 5 Entlastung und Verabschiedung des Vorstands

- TOP 6 Vorstellung der Kandidaten für 2012-2015

- TOP 7 Wahlen des Vorstands 20122015

- TOP 8 Sonstiges 